Article

\title{
Writing Lifestories: A Methodology Introducing Students to Multicultural Education Utilizing Creative Writing and Genealogy
}

\author{
Paulette T. Cross \\ Department of Professional Learning \& Innovation, Georgia College \& State University, Milledgeville, GA 31061, \\ USA; paulette.cross@gcsu.edu
}

Received: 10 February 2020; Accepted: 9 March 2020; Published: 16 March 2020

\begin{abstract}
In this article, the author describes how she used a university course book assignment to produce a family history book to: (1) Raise consciousness and deepen understandings of other cultures, (2) assist students' understanding of how intersecting cultures become part of the complex American cultural landscape, and (3) introduce students to research utilizing genealogical tools. The assignment aims to provide freshmen and preservice teacher education students an opportunity to recover personal memories and retell family stories, meld personal fragments into context by researching the historical and cultural backgrounds of their ancestors and produce a work that captures the interior life of a culture where each of us came. This calls for using "historical memory" to recover personal memories and retell family stories. Lastly, the knowledge gained from the Writing Lifestories: Exploring Cultural Heritages' (2019) course will help students understand and heighten an awareness of multiculturalism/multicultural education through creative writing and immersion into research.
\end{abstract}

Keywords: memoir; genealogy; family history; storytelling

\section{Introduction}

I believe educators affect change in student attitudes, beliefs and values over time based on their epistemic and pedagogical underpinnings. In the case of multicultural education and the intersectionality of race, class, gender, ability, disability, LGBTQ, and capitalism-All course discussions are focused in historical contexts; and therefore, may become uncomfortable for many students. So, how can we, as educators, engage students in serious discussions about life intersections without disengaging them? This article answers this question through demonstrating a course design and implementation of writing lifestories, where students ultimately produce a family history book as memoir (e.g., family stories or narratives) for their final book assignment. The "writing lifestories'" course is grounded in an historical context and utilizes genealogical tools.

This course offers resources to the students which show the value of cultural competence and move beyond the nation's past dark history of oppression and injustice. This course explores the following questions: How will the content resonate and/or engage the students? What do the methodological understandings reveal? How will the challenges of writing lifestories through memoir (i.e., recalling memorable incidents and researching family members in order to complete a 100-page family history book by the end of a 15-week course) reveal itself?

First, I discuss the origin of the course and my experience in taking a "writing lifestories" class two decades prior with Dr. Yamada. In retrospect, my positionality of 50 years' experience over the course of time generated production of knowledge via my family stories, obtained genealogical tools and created the Newton-Patrick-Smith family history book. Second, I discuss the journey of 
designing a course utilizing Dr. Yamada's syllabi/research to connect to the sign of the times-e.g., 21st century politics where students learn to think critically about social issues of race, gender, social class, immigration, capitalism, and historical representations of race/racism that I use, frame course themes through engagement in the production of family history books. I've not found another course like this in a national review. Third, I reflect upon my interpretations about the literature and my own pedagogical decisions about design in relation to critical theory literature and my prior experiences as a student to engage the students in my course responding to the book assignment (which includes excerpts from Dr. Yamada's syllabi in comparison to mine). Also, I reflect on student work, observe the course functions, and analyze various student writings throughout the semester. Lastly, I conclude with the implications for using this assignment and the challenges of my class. Again, I rely on research from Dr. Yamada's course syllabi to support my interpretations about my own experience with the writing lifestories course at Georgia College.

\section{Origin of the Course}

The context of the course starts with my recounting the story about my enrollment in a "writing lifestories'" course as a freshman in college. Unbeknownst to me at the time, I would reproduce, design and implement a similar course as it was taught to me in college. Imagine the impact of that professor (e.g., Dr. Yamada) who taught the course then. It changed my life, and because of the impact, I am now teaching a similar course in "writing lifestories" at a small liberal arts teachers' college in middle Georgia. When I attended college at that time, I was exposed to scholars such as Lisa Delpit, Sonia Nieto, Gloria Ladson-Billings (teacher education), bell hooks, (black feminist and cultural critic), Toni Morrison (author/educator and cultural critic), Christine Sleeter (critical family history), Joyce King (dysconscious racism), Alice Walker (womanist, novelist, essayist poet, and social activist), Paulo Freire (pedagogical theory and cultural studies), Edward Said (cultural studies and imperialism), homi bhabba (cultural difference and the third space) Derrick Bell (professor, lawyer, civil rights activist, and critical race theorist/Space Traders), and Stuart Hall (cultural studies and locations of culture). As overwhelming as this must seem to a freshman (and even doctoral students), it truly demonstrates how the caring and influence of one professor, exposing students to epistemological and pedagogical ideals, shaped my perspectives about teaching and learning that led to the creation of me designing a course entitled, "Writing Lifestories: Discovering Cultural Heritage".

It is an exciting moment when one is at the apex in life and begins to affect change and witness the excitement in the students enrolled in such courses, as a result. The following narrative reifies many nuances of a "writing lifestories" course from the design, function, observation and witnessing specific learning goals of the course, to the idea that years after taking this course, students will be able to:

- Organize their experiences and write personal stories.

- Interview family members (and others) and capture their experiences in your own prose.

- See and experience the world as those who came before them may have seen and felt it in order to understand ancestors hopes, dreams, and fears.

- Reflect upon how family history affected their lives in order for them to gain the insights needed to capture the interior life of a culture from whence they came.

- Explain to others that regardless of what heritage we come from, ALL are part of rich and varied backgrounds and intersecting cultures have become a part of the complex American cultural landscape.

- Research historical materials in order to put their own lifestories into the context of a wider world around them and take responsibility for the space that they occupy.

- $\quad$ Produce writings that will hopefully become valued family resources and treasures. 


\section{Designing the Course for a New Generation}

Following my participation in a professional development course entitled, Design for Transformative Learning (Alby 2019), I began constructing the "writing lifestories" course. I spent the entire Fall 2019 semester working with students toward culminating a family history book. Students would need to analyze effective methodological approaches used for critical family histories through a collection of reading and writing assignments across the semester. Each assignment has been carefully designed to facilitate students' research process, methodological understandings, and argument construction as a chapter or meaningful component of the culminating family history book. Therefore, students identify what successful modes of writing and analysis inform their own lifestories (see Appendix A).

All writing assignments, which receive scaffolding and feedback along the way, are prospective chapters from which students can select to include in their written argument synthesizing how their own family connects to local and global contexts through their critical family history composition. Students must demonstrate the ability to communicate not only facts or a family timeline, but also the intersections of power, social class, race, capitalism, as well as individual and collective experience. For example, the "Bibliography Assignment" from Week 10 supports students in articulating and annotating how they have engaged in a full review of related literature and sources to identify the five (5) most important scholarly sources used for their projects. This includes primary and secondary source materials of historical books and articles, cultural research, and genealogy. Students must evaluate each source for relevance, authority and format. Finally, students explain their critiques, including all sources listed in the bibliography.

\section{Interpretations about the Literature and My Pedagogical Decisions}

In an effort to challenge student understandings about literature, particularly home and family as related to family narratives, I integrated Sleeter's theorization of critical family history to provide an overarching theoretical framework to model and support critical thinking and the literature. Social issues (e.g., race, gender, social class, immigration, capitalism, and historical representation) are key to informing critical thinking. Therefore, as previously stated, the course utilizes readings from Hooks (1990), Morrison (1995), Walker (2002), Waniek (1990) and Dilworth-Williams (2002) as scholars who powerfully describe "home and family". Scholars such as Goldberg (1996), Trueblood and Stovall (1996) discuss Americanness, Nativeness, Asianness and many other identities in this spectrum, including gender.

Dr. Yamada, in conducting her Writing Asian American Life Stories: Exploring Cultural Heritage (Yamada 1997, 1999, 2000, 2003) course readings, carefully selected the literature in order to foster student engagement and critical thinking regarding the scholars and/or scholarly texts utilized in her course. In the 2019 writing lifestories course that I designed, I relied heavily on many of those texts, as well as augmenting my course with the above-mentioned scholarly texts. I believe the uniqueness of both courses are the deep connections students engage in across literatures and processes.

In an excerpt from Dr. Yamada's syllabus dated Winter Quarter, 1999, she directs her students through reading and writing assignments by integrating prompts to assist them in thinking about their parents, grandparents, and conceptualizing home:

"Read: The Rice Room: Number Two Son to Rock and Roll by Fong-Torres

Written assignment: Write 2-4 pages in a typewritten, double spaced paper. Do any of the topics Torres writes about ring a bell with you? (e.g., your relationship with your parents today (Prologue). Do certain foods remind you of "home?" Your parents? Certain childhood experiences? (Chapter 1). Are names, or what we call ourselves, an issue with people with "different" sounding names? What was your relationship with your siblings? What were your childhood passions? Have you ever openly defied your parents as Fong-Torres did?

Written Assignment: Now, write a 3-4 page paper about your grandparents. Do some research on historical/political context. If your grandparents are not available to interview, 
interview your parents to learn what they remember about them, or even a friend of the family or a contemporary of your parents/grandparents. Look up historical incidents mentioned by your contacts".

(p. 3)

In addition to the theme of "home", Dr. Yamada selected this memoir to introduce students to the idea of double identity (i.e., Chinese and American) so they could reflect on popular culture (Hong's love of Elvis Presley), American lifestyle and one's national identity juxtaposed against tradition and cultural heritage.

Dr. Yamada, in the second week of the course, begins to utilize written assignments that are analytical in nature, such as The Rice Room (Fong-Torres 1994), to guide student thinking. Her syllabus indicates the length and nature of required writing, suggests an analytical response via a two to four-page paper length, with the minimum and maximum words the student should use. Dr. Yamada also utilizes "scaffolding" techniques as she grades the papers and gives feedback to each student. This allows them to revise their papers appropriately. Students analyze their ideas in written form as the course progresses.

Mirroring Dr. Yamada and engaging a different demographic in the 21st century, I conducted my newly designed course, "Writing Lifestories: Exploring Cultural Heritage" (Georgia College \& State University 2019) in the Fall semester by incorporating poetry (as Dr. Yamada did throughout her courses, since she was a poet) to engage as a way to conceptualize homeplace. The following are examples:

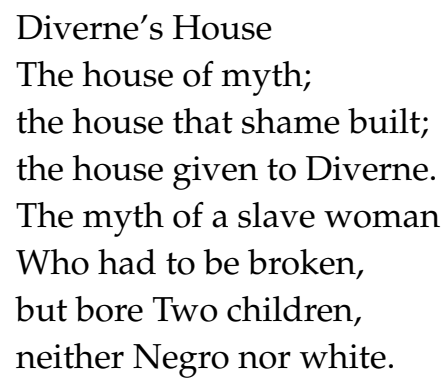

Diverne's House

The house of myth;

the house that shame built;

the house given to Diverne.

The myth of a slave woman

Who had to be broken,

but bore Two children,

neither Negro nor white.

The myth of their father. (Waniek 1990)

Panola: My Kinfolks' Land

As the toilers laid their tools down for an endless rest.

It's on this site that my soul breathes to harvest my best.

For what was planted by those before me will forever stand.

On this rural countryside called Panola, my kinfolks' land. (Dilworth-Williams 2002)

Waniek (1990) and Dilworth-Williams (2002) excerpts above are examples of ways in which homeplace frequently occurs in the poetry of African Americans and is representative in oral traditions and historical stories that show the importance of homeplaces. Specifically, their poetry functions as a theoretical tool in which to conceptualize homeplace as a safe space for racial socialization (Cross 2014).

Poetry as theory demystifies the story of Waniek's ancestral grandmother Diverne's house, where homeplace is the setting in which she weaves a complex story about genealogy, family relations, the injustices of slavery, compassion and dignity. Diverne is the great, great, great grandmother of Waniek. Another example of Waniek's homeplace, is seen in her poem, "The House on Moscow Street", where we envision the rituals embodying homeplace:

It's the ragged source of memory, a tarpaper-shingled bungalow in a weedy ravine

Nothing special: a chain of three bedrooms and a long side porch turned parlor where my great-grandfather, Pomp, smoked every evening over the news, a long sunny kitchen where 
Annie, his wife measured cornmeal dreaming through the window across the ravine and up to Shelby Hill where she had borne their spirited, high-yellow brood ...

(Waniek 1990, p. 4)

Waniek's family history prevails in this verse as she describes the house and introduces issues of socio-economic status and class. Her poetry shows us the ordinariness of life, such as the daily rituals a person encounters in the homeplace: Smoking, preparing meals, and the introduction of the notion "bi-racialness" as the poet discusses forbidden and love relationships, ancestors, and the pride the family has in land ownership. Most importantly, food is a major theme, along with loss and the idea of reunification:

... As much love,

As much as a visit

To the grave of a known ancestor,

The homeplace moves me not to silence But to righteous, praise Jesus song:

... Oh, catfish and turnip greens,

Hot-water cornbread and grits

Oh, musty, much-underlined Bibles; Generations lost to be found, to be found.

(Waniek 1990, p. 4; Cross 2014)

Much is learned by the students from Waniek's poem. Not only does it give us a glimpse into the lives of Pomp and Annie's house on Moscow Street, we observe the inner makings of a home as we witness their everyday, ordinary lives. We imagine through the rich, descriptive narrative the dinner meal of "soul food", the historical nature of the house as a home, the genealogical link to the ancestors, and the spirituality that drives the family forward.

As the students read Dilworth-Williams (2002) book of poetry, Panola: My Kinfolks' Land, it assisted them (as it did me) in recognizing and theorizing why the connection to land-the homeplace-resonates. Dilworth-Williams' descriptive imagery about her homestead encapsulated and transported me in a time machine to the past-Warsaw, Virginia. I read this book 13 years after my cousin, Phyllis, and I visited the Newton family's ancestral graves located at Clarksville Baptist Church; and as I recall, Dilworth-Williams' poems conjured up wonderful and chilling feelings in me simultaneously as I expressed below in an excerpt from my family history booked, WARSAW: The Newton-Patrick-Smith family history book (Cross 1997) produced in Dr. Yamada's course and now added as contextual material to my course. For example:

I interrogated the two following photographs as data from a family history exhibit, Our Homestead (Figure 1) and the Clarkesville Baptist Church (Figure 2).

The family's homestead (Figure 1) is located in Richmond County, the village of Warsaw (near Lyells), Virginia. Isabelle Newton (my great, great, great grandmother) bought this land as a result of saving money from the wages she earned as a midwife. The land-a total of 6 to 8 acres—was purchased from the Carter family (" ... good White people") for $\$ 40$.

“... site of the ancestor ... The role of the ancestor in Southern sections ...

Is of great significance because it stress(es) the significance of an ancestor, or the blood ... a place where Black blood earns a Black birthright to the land, a locus of history, culture ... a place of birthright ... a significant Influence in the migrant's life in the North."

Who Set You Flowin? (Farah Jasmine Griffen 1995)

“... the Black South's religiosity ... provided psychic health for Blacks by assuring them that they would not always be oppressed in the "Egyptland" of the Jim Crow south [but] 
equipped Southern Blacks with an indigenous belief system for hastening and contributing to their own liberation."

Caron (1996)

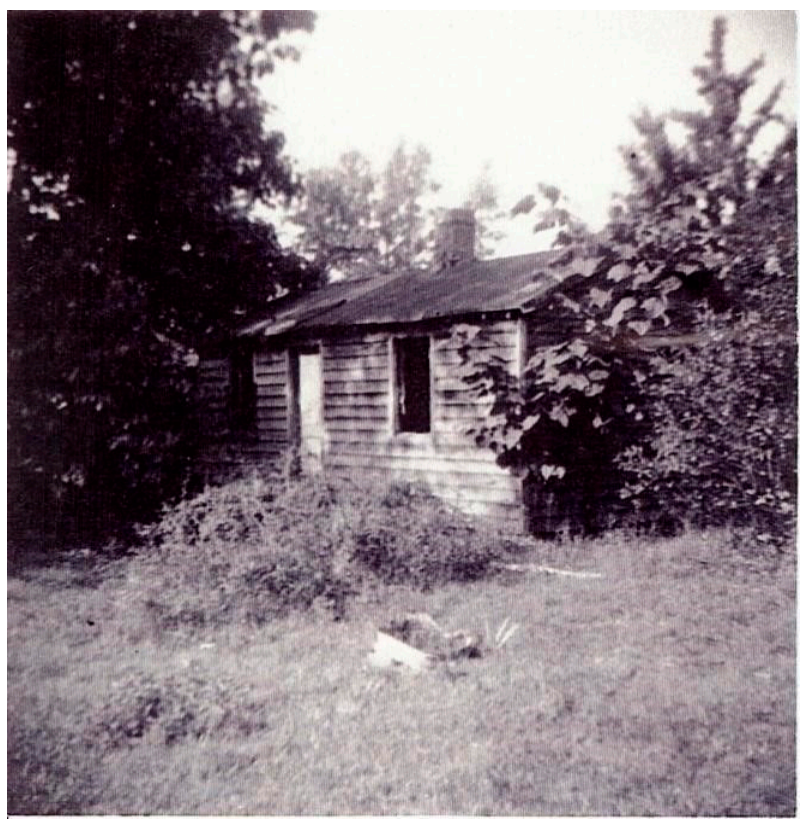

Figure 1. Our Homestead. (Photograph: circa 1950s—courtesy of Viola Wilson).

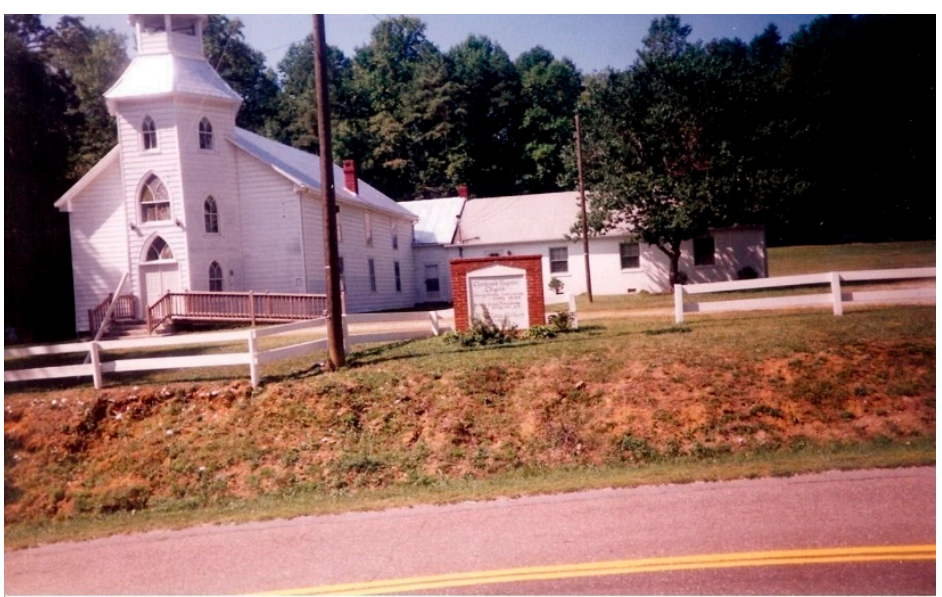

Figure 2. Clarkesville Baptist Church.

It is believed that this church is about 200 years old, and it is told that the Newton family was affiliated with it most of that time. Most of the family who lived in Warsaw went to Clarkesville Baptist Church and are buried in the cemetery behind it on Effel Road, the street where the church is located in Warsaw, Virginia (Photograph: Circa 1997 courtesy of Phyllis Smith). As I reconstructed the image of this photograph by adding a U.S. Black historical context to the Newton family history ... I connected Griffen's (1995) excerpt to pull in themes surrounding the South, site of place, and the roles of ancestor and kinship. Earlier in the study, I discussed Virginia's stories which centered the Newton family's connection to their ancestors, the land, the family's church and the community. By exhibiting the photographs of the family and their possessions, we instill the family's pride. Pictures become a source of our heritage and live on to become permanent images of the Newton family. Using photographs in this way continues to transmit the stories for posterity (Cross 1997). 
This addition to my syllabus (i.e., the addition of my family history book to the course) differentiated the choice of literatures necessary to engage my students is a distinction between Dr. Yamada's course and mine. My family history book is a model of the finished product and an example of the scaffolding that takes place in the classroom and the engagement that follows, because students are eager to understand the connections between their family history when contrasted to mine-a real life example. The conceptualization of home and family begins to resonate, based on utilizing such in-class models. Integration of my family's history into the course supports a conceptualization of "homeplace"-i.e., an intersectionality between the ordinary, everyday lives of the people and their land and the houses as the place they call home assists student understanding.

Lastly, Waniek (1990) and Dilworth-Williams (2002)homeplaces are viable theoretical tools. In comparison to empirical studies, these theoretical tools about homeplace provide conceptual guidance. Poetry tells us how the homeplace provides a sanctuary-a place where African Americans can embrace renewal and physical, mental, and emotional healing from frequent subtle and overt discriminatory assaults experienced by African Americans in predominantly White environments.

Dr. Yamada's second excerpt from her syllabus dated Fall Quarter, 2000, guides student research to push students to begin conceptualizing about the idea of "home" as related to its occupants-the parents, grandparents, aunts and uncles, etc., through short reading assignments and exercises:

"Reading assignment: "First Memories", in Hong's Growing up Asian American: An Anthology (Hong 1993, pp. 21-123). Some of the memories described in these short excerpts may help you in your interviews with your parents/grandparents about their childhood memories. Interview your grandparents or your parents, or both. If your grandparents are not available to interview, interview your parents to learn what they remember about their own childhood, or even a friend of the family or a contemporary of your parents or grandparents.

Short introduction to the readings.

Discussion of possibilities: How to begin research on your own family. Genealogical Research. Make plans for interviews; i.e., collect materials immediately accessible to you.

Write down names of family members you can consult, names of family friends and contemporaries of parents, grandparents.". (p. 3)

For example, she utilizes the first assignment, "A Collection of Memories" to introduce writing processes and to brainstorm about family history and historical contexts. Students start collecting material for their book project, e.g., names of family members to consult (telephone numbers, addresses), family friends and contemporaries of their parents and grandparents. They start making plans for interviews immediately.

In contrast, in my course, I incorporated several class sessions involving library research as the below-mentioned excerpt reveals:

“Guidelines for Library Research

There are three Library Research Days when you will report to the library to research materials for your Family History Book. Take advantage of the time and explore the library resources such as Ancestry.com, Dr. Christine Sleeter's blog (https://christinesleeter.org/critical-familyhistory/), and any other library resources. Use the following guidelines to assist you with the research:

Research the historical background of the period: major news events, prominent political figures, economic or religious trends. 
Collect visual images, old family photographs if available, if not, other images in books and magazines. Describe what the world must have looked like to your ancestors: Architecture, street signs, dress and hair styles, advertising, and foods.

Research cultural milieu: Artistic trends, best seller books, popular songs, jokes, recreational activities, games, movies, medical practices. Submit the primary sources where available into GeorgiaView (i.e., letters, newspapers clippings, documents).

Sign of the times: Speculate on the hopes, dreams, fears of the period. Examine the editorial sections of the newspapers, letters"

Each student must submit a 1-page, double-spaced response paper assignment to GeorgiaView (Georgia College \& State University 2019).

\section{Reflections Upon the Initial Implementation}

\section{Conclusions}

Implications of this course comprise two demographics of participants that I will discuss; namely, many with different experiences beyond academia (such as community residents) and those who might experience pain or uncomfortableness as a result of their family research. What approach is useful or accommodates the writing process in these instances? This course is designed to teach in a higher education environment focusing on a diversity of Americans. But, in some ways, the context is open-ended in that it could be taught in many different ways. For example, I will teach the course to community residents to bridge the gap between community residents and higher education, giving them an opportunity to experience a "writing lifestories" course. Community residents are unlike college students, because students matriculate to higher education based on pursuit of academic credentials. Thinking outside of the box, teaching this course to community residents that includes various educational challenges-e.g., engagements are representative of diverse populations from all walks of life. For instance, some participants enrolling in the course might not have visited a college campus. As a result, challenges arise from issues of literacy and disabilities to uncomfortableness, ability, etc. Therefore, a certain amount of flexibility is required to support all students. Another example is the theme of social justice that runs throughout many historical contexts in the Writing Multicultural Lifestories in Communities. This falls within the discipline of anti-racist pedagogy, touching many lives through the intersectionality of race, class, gender, ableism, LGBTQ—all issues addressed as community residents research and write their Family History Books (which also could be formulated from a global context since this theme is universal).

Lastly, I highlight a piece of prose below (that I use in my course that speaks to difficult, uncomfortable familial situations) that my cousin Akiba wrote and sent me after the death of her "grandpop" (who was my maternal uncle), that speaks to the negativity and/or complexities surrounding reconstructing family relationships where none existed previously:

Cousin P

Or should I call her Cousin Suicidal-out there in

Mormonville, UT

But a girl's gotta get edukated!

smile

Anyway, it was GrandPop's viewing

I knew all of 8 people in the room

I was nervous and needless to say not looking forward to sitting in a room with a "body"

Not my Pop

Shoooooot, we used to watch Soul Food on HBO

He called them "the stories" 
He introduced me to a new word: "bulldagger"

That was a brand new word

He used to watch Moesha, Hardball with Chris

Matthews and Judge Mablean all at once

Thats right, $3 \mathrm{tv}^{\prime} \mathrm{s}$ on at the same time

I was blessed enough to meet him in '97

He and my mother had the same smile My mother showed me forgiveness through her relationship with him

He was a cool dude-and he knew it

"These are Stacey Adams... the only shoes I wear", he informed me with that Grandaddy arrogance and charm once, when I complimented him on his shoes

Saying goodbye to him messed me up

But God was with me

And so was Cousin P

Before I stepped a foot into the room

I looked up and there was my cousin Paulette My cousin who'd spent all of 8 min with me

my whole life

I just knew her cause I'd never ridden in a Benz til she came to visit

She walked me over to the casket

And when I was about to crumble, she was next to me literally holdin me up

God just sent her-

And the two of them were right on time.

The setting of Akiba's poem is her Grand Pop's funeral at Kniffen's Funeral Home in Wilkes-Barre, Pennsylvania. Funerals, like family reunions, are family gatherings where one sees the functioning of the family. Clearly, the characteristics of many Black families are exhibited at funerals: The love of family members, othermothering, and the functioning of a family during sad times is demonstrated in Akiba's prose. Akiba speaks to a sense of loss that she has experienced intergenerationally-an inheritance, so to speak, from her mother-in two ways. Firstly, she discussed the loss of her grandfather Lawrence, whom she recently met a few years prior to his death. Secondly, Akiba connected her grandfather's loss to the non-existent relationships in which she was not a participant in the Newton family. This feeling compounds the notion of loss for her family, suggested by the short time in which she was reunited with her cousin Paulette.

I use this example in the "writing lifestories" course, not only to introduce students to the notion of grief, uncomfortableness and issues surrounding difficulty in expressing or uttering their emotions; but also, as a way in which to grapple with the truth of family histories through writing.

Conflicts of Interest: The authors declare no conflict of interest. 
Appendix A

\begin{tabular}{|c|c|c|}
\hline Assignment & Length and Format & Contribution to Argument Construction \\
\hline \#1 A Collection of Memories & Brainstorming over $2-3$ pages & Initial writing process brainstorming draft of family history and historical contexts \\
\hline \#2 A Response to Partner Scholar Presentations & Reflection of $2-3$ pages & Synthesis and analysis of material presented by a range of scholars \\
\hline \#3 A Memorable Incident in My Life & Reflection of 2-4 pages & Data collection and synthesis \\
\hline \#4 Interview with a Family Member & $\begin{array}{l}\text { Data collection and initial analysis. Length will vary, but } \\
\text { likely 2-4 pages }\end{array}$ & $\begin{array}{l}\text { Learning to synthesize specific data sources within broader contexts. Students work } \\
\text { on identifying facts with accuracy, connecting to other sources, and beginning to } \\
\text { identify theme. (Family member's perspective). }\end{array}$ \\
\hline Midterm Table of Contents & Midterm outline, $1-2$ pages & Synthesizing key data and initial thesis construction. \\
\hline \#6 Narrative of Findings & Reflection of $2-4$ pages in a scholarly paper format & $\begin{array}{l}\text { Connecting interview data as well as research from primary and secondary sources } \\
\text { to begin a deeper synthesis leading to the overarching thesis and argument. }\end{array}$ \\
\hline \#7 An Analytical Essay & Reading response of $2-4$ pages & $\begin{array}{l}\text { Students respond to specific readings and model scholarly texts (e.g., Bell Hooks' } \\
\text { Yearning: Race, Gender and Cultural Politics). The assignment requires students to } \\
\text { read and respond to scholarly work written in a similar format to their culminating } \\
\text { project. }\end{array}$ \\
\hline \#8 National Identity & Reflective reading response of $2-4$ pages & $\begin{array}{l}\text { This assignment guides students to examine their ethnic identity and how it relates } \\
\text { to family history and context. This is a seminal assignment for the scholarly } \\
\text { connection between individual families and broader social and political contexts. }\end{array}$ \\
\hline \#9 Conclusion & Synthesis for inclusion in the culminating project, $2-4$ pages & $\begin{array}{l}\text { This is the final "chapter" or writing selection in the culminating book project. This } \\
\text { is the location of the overarching argument each student constructs for their family } \\
\text { history book. }\end{array}$ \\
\hline \#10 Bibliography & $\begin{array}{l}\text { Annotated bibliography, varied in amount of pages. } \\
\text { (approximately } 2 \text { pages) }\end{array}$ & $\begin{array}{l}\text { Students articulate and annotate how they have engaged in a full review of related } \\
\text { literature and sources to identify the five (5) most important scholarly sources used } \\
\text { for their projects. This includes primary and secondary source materials of } \\
\text { historical books and articles, cultural research, and genealogy. Students must } \\
\text { evaluate each source for relevance, authority and format. }\end{array}$ \\
\hline Final Culminating Book & Initial and final draft of the culminating family history book & $\begin{array}{l}\text { Course synthesis and argument presentation. These books are shared in the library } \\
\text { with an abstract and full text showcase. }\end{array}$ \\
\hline
\end{tabular}




\section{References}

Alby, C. 2019. Design for Transformative Learning. Semester-Long Program. Milledgeville: Center for Teaching and Learning, Georgia College \& State University.

Caron, Timothy P. 1996. The-reds-are-in-the-Bible-room-political activism and the Bible in wright, Richard 'uncle tom's children'. Studies in American Fiction 24: 45-64. [CrossRef]

Cross, P. 1997. WARSAW: The Newton-Patrick-Smith Family History Book. Unpublished book. Irvine: University of California at Irvine.

Cross, Paulette Theresa. 2014. HOMEPLACE: Unearthing and Tracing the Oral Traditions and Subjugated Knowledge of a Multi-Generational Woman-Centered African American Family. Ph.D. dissertation, The University of Utah Education, Culture \& Society, Salt Lake City, UT, USA.

Dilworth-Williams, Evelyn. 2002. Panola: My Kinfolks' Land. Bloomington: AuthorHouse.

Fong-Torres, Ben. 1994. The Rice Room: Growing Up Chinese-American from Number Two Son to Rock ' $n$ ' Roll. Berkely: University of California.

Georgia College \& State University. 2019. GC1Y 1000: Critical Thinking: Writing Lifestories_Discovering Cultural Heritage Syllabus. Milledgeville: Paulette Cross.

Goldberg, Natalie. 1996. Writing Down the Bones. Boulder: Shambhala Publications, Inc.

Hong, Maria. 1993. Growing Up Asian American: An Anthology. New York: W. Morrow.

Hooks, Bell. 1990. Homeplace: A site of resistance. In Yearning: Race, Gender, and Cultural Politics. Boston: South End Press.

Morrison, Toni. 1995. The Site of Memory. In Inventing the Truth: The Art and Craft of Memoir, 2nd ed. Edited by William Zinsser. Boston and New York: Houghton Mifflin, pp. 83-102.

Trueblood, Kathryn, and Linda Stovall. 1996. Homeground. Ann Arbor: University of Michigan: Before Columbus Foundation.

Walker, Alice. 2002. Everyday Use. New York: Knopf Publishing Group.

Waniek, M. N. 1990. The Homeplace. Baton Rouge: Louisiana State University Press.

Yamada, Mitsuye. 1997. Asian Am 110/Com Lit 103: Asian Americans Writing Lifestories: Discovering Cultural Heritage Syllabus. Irvine: The University of California at Irvine: School of Humanities.

Yamada, Mitsuye. 1999. Asian Am 110/Com Lit 103: Asian Americans Writing Lifestories: Discovering Cultural Heritage Syllabus. Irvine: The University of California at Irvine: School of Humanities.

Yamada, Mitsuye. 2000. Asian Am 110/Com Lit 103: Asian Americans Writing Lifestories: Discovering Cultural Heritage Syllabus. Irvine: The University of California at Irvine: School of Humanities.

Yamada, Mitsuye. 2003. Asian Am 110/Com Lit 103: Asian Americans Writing Lifestories: Discovering Cultural Heritage Syllabus. Irvine: The University of California at Irvine: School of Humanities. 